with apparent approval, from Mr. Watson Cheyne's lecture, as follows: "The peritoneum has marvellous powers of absorbing fluids, and thus effusions into it are very rapidly removed, and in this way micro-organisms are deprived of the necessary nutrient material, while they are also in all probability absorbed along with the fluid and destroyed in the blood or excreted." This is precisely the contention for which those who, like myself, have been sceptical all along both as to the theory and practice of the so-called aseptic surgery have been arguing. For my own part, I have always held that it is the pabulum upon which germs may feed that we have to deal with, and not the germs.

The conclusion, therefore, that I arrive at is that the improvements in modern surgery are due in the first place to the introduction of the drainage tube by Chassaignac and the absorbent cotton-wool by Gamgee, and that the theory and practice introduced by Lister were alike mistaken and misleading. This has been proved completely by the results of peritoneal operations; and though Mr. Watson Cheyne indulges in an inconsistency by attempting an explanation which would lead us to believe that the peritoneum and its contents differ in their processes from other tissues of the body, those of us who are concerned in dealing with them every day know that this is not so. If proof were needed further, it can be afforded in the case of removal of the breast, an operation which I perform very frequently, and in which I have obtained results by means of the drainage tube and hydrophile cotton infinitely superior to anything which can be shown by the most elaborate aseptic process. That there is anything better in general surgery to be obtained by the numerous and constantly differing details introduced and advocated by Lister and his followers no real proof has ever been attempted. If it could be shown that out of a thousand amputations below the knee, performed with strict so-called aseptic details, there was a very much less mortality than without the adoption of such details, we might be inclined to accept something of what Mr. Christopher Heath and Mr. Watson Cheyne seem to argue for. But no one has attempted in the most elementary degree to tabulate the statistics of such common operations, far less to report them on the strict principles adopted by us for our abdominal sections; and the hospital of all others from which we might expect some kind of statistical argument in favour of Listerism-King's College Hospitalis the one from which no kind of human effort seems capable of extracting information.

I am, Sirs, yours faithfully,

Birminghxin, July 11th, 1888. LAWSON TAIT.

\section{WHAT IS THE PRESENT POPULATION OF OUR LARGE TOWNS?}

To the Editors of THE LANCET.

SIRS,-This question, to which you called attention in your last issue, is one of especial importance to medical officers of health, and I would urge the desirability of those gentlemen supporting the recent memorial of the Royal Statistical Society to the Local Government Board in favour of a quinquennial census. That the present official estimates of populations are in many cases quite untrustworthy is admitted on all hands, but similar estimates, if checked by an enumeration every five years, would be sufficiently close for all practical purposes. I submit that not only is the population of individual towns a matter of uncertainty at the present moment, but even the population of the whole country. ${ }^{1}$ The increase of emigration and the great fall both in the birth-rate and the death-rate cannot but have had a notable effect not only on the number but also on the age-constitution of the population, so that to-day we cannot be said to have any solid basis upon which to found vital statistics; moreover, we shall be yearly in a worse and worse condition until the figures of the next census see the light. $I$ would remind your readers tliat a quinquennial census is taken in the following countries-Germany, France, New Zealand, Queensland, Manitoba, the North-West Telitory of Canada, and several of the Lnited States (twelve States and three territories). Why should England, the richest country in the world, that in which the population question is most urgent, and the generally admitted leader in all matters related to preventive medicine, lag behind in this one respect?-I am, Sirs, your obedient servant,

Wandsworth, July 14 th, 1388.

G. B. LoNGSTAFF.

1 See Journal of Statistical Society, 1886, pp. 760-3.

\section{OSTEO-PLASTIC RESECTION OF THE FOOT}

To the Editors of THE LANCET.

SIRS,-Will you kindly allow a few remarks in criticism of Mikulicz's operation, as described by Sir Wm. Mac Cormac in your issue of May 5th, which has but just reached me. I do not of course impugn Sir W. Ma乞 Cormac's selection of an operation for the very successful case he describes and figures, but refer simply to the indications for such an operation, which it appears to me are few and rarely met with. The doubtful points in the Mikulicz method seen to be-(1) the sacrifice of the heel as a means of locomotion (2) the extensive removal of soft parts; (3) the ankylasi with the metatarsus in the line of the limb.

In 1885 I performed the following operation, of which a brief account was published in the Kashmir Mission Hos pital report for that year. I quote verbatim :- "The patient, a lad, had disease of the tibia, ankle joint, and tarsus. At first amputation seemed inevitable. But his constitution was good. I therefore began by resecting the diseased tibia, a portion five inches long. Within two months the wound was healed. By a second operation I removed the tarsal disease, fortunately limited to the astragalus and os calcis. Within six weeks the patient was able to wall about, and the deformity fron flatness of the heel was slight." In this brief digest, which I trust some day to supplement by a full one, several salient facts were omitted. The tibia was perfectly replaced by its periosteum. The epiphysial cartilage was left untouched by either operation, the second of which was an excision of the ankle joint and a partly subperiosteal removal of the two bones mentioned. I had expected to remove the rest of the tarsus, but found it healthy. During the after treatment the foot was fixed in a line with the leg on straight splint. Thus at first there was hardly any cavity left. I expected a sort of ankylosis in this position. But the growth of new tissue began soon to fill out the heel, and I therefore allowed the foot gradually to resum? its natural position. The result, as a sketch taken at the time shows, was a mobile, useful, and almost undeformed foot. I have no doubt many somewhat similar cases have been recorded, in addition to that of Dr. Swann in your issue of May 19th, and I do not write to claim priority or special originality, but to elicit the opinions of those who have practised extensive resections as to the sphere of the so-called "osteo-plastic resection of the foot." There may be cases in which it is impossible or undesirable to retain the heel, and possible to retain the anterior part of the foot. These, and these only, appear to me to indicate Vikulicz's operation; such cases, for example, as gunshot wound of the heel and ankle, or disease of the tarsus with extensive implication of the skin of the heel. Apart from such disease or injury of the soft parts of the heel, indications for removal of the posterior and most important arm of the foot-lever must be rare. The opera. tion is indeed an amputation of the heel, and its result is stump ending in toes. It is even open to question whether the result is as useful as or more sightly than a Syme's amputation. It is certainly far inferior to the eventaal results of a successful resection of the tarsus and ankle joint both in appearance and utility; but if it be reserved for such cases as I have indicated above, neither the ordinary methods of resection nor a Syme's amputation come into competition with it.

I am, Sirs, yours obediently,

ARTHUR NEVE, F.R.C.S. ED.

Kashmir Mission Hospital, June, 1888.

\section{MAJOR AMPUTATIONS TREATED ANTI- SEPTICALLY. \\ To the Editors of THE LANCET.}

SIRS,-Mr. Frederick Page, in THE LANCET of last week, records the fact that in the Newcastle-on-Tyne Royal Infirmarr during the last year sixty patients were submitted to sixty. two major amputations (upper and lower extremities), and that the mortality was two persons, being a death-rate of $3 \cdot 3$ per cent. I freely admit the excellence of such an unusual result, but, as one of those who are much interested in statistics of the above kind, I feel that the interest. value, and importance of such would be increased and made more complete if $\mathrm{Mr}$. Page would mention the age of the 
patients operated on, and would also be good enouch precisely to define what is implied by the word "antiseptically."-I am, Sirs, yours faithfully,
Wolverhampton, July 15th, 1888 .
T. VINCEN'T-J $\Lambda$ CKSON.

\section{NORTHERN COUNTIES NOTES. \\ (From our own Correspondent.)}

THE SICK CHILDREN'S HOSPITAL: PROPOSED ROYAL VISIT TO NEWCASTLE.

AT a meeting of the Sick Children's Hospital Committee, held on Friday last, the May or presiding, Mr. John Fleming reported his interview with Lord Armstrong relative to the proposed visit of his Royal Highness Prince Albert Victor to Newcastle on the opening of the new hospital so handsomely erected and furnished by Mr. Fleming. It was understood from a communication made that the Prince of Wales favoured the idea, and promised to carry out the arrangement if possible. Lord Armstrong will entertain the Prince at his seat (Craigside, Rothbury), and it is anticipated that the hospital will be opened about the first week in September next. If the Prince could be induced to open the new College of Medicine here, should it be so far advanced by the time, it would be an advantage. I have already mentioned that a portion of the College is to be ready for use in October, but I fear the present weather is not favourable to the progress of building operations.

TYNEMOUTH POLICE AMBULANCE CORPS.

The borough of Tynemouth Police Ambulance Corps have been lately examined by Mr. Frederick Page and Mr. G. E. Williamson, lecturers at the College of Medicine, and surgeons to the Newcastle Royal Infirmary. Dr. W. P. Mears was the instructor of the class. The men, thirty in number, were put through a variety of manceuvres well contrived to show their skill and knowledge of first aid to the injured. The men were commended for their knowledge by the exaniners, and Dr. W. P. Mears was complimented by them for his successful instruction, and the whole of the men would be recommended for certificates to the University of Durham. It is right to mention that there has been some correspondence on this subject in our local papers, the witers contending that the University of Durham is trenching on the work of the St. John Ambulance Association; but surely there is work enough for both in this department, and the University of Durham has at least a right to instruct and certify in its own district. The letters I refer to were all anonymous, and are therefore deficient in the weight which they perhaps might have had if the writers had given their names.

\section{STOCKTON AND MIDDLESBROUGH.}

Dr. Halcolmson, medical officer of health at Middlesbrough, has published a report in which he says that up to the present time only five deaths have occurred in the borough from pneumonia during the present month, being at the rate of fifteen per month, whereas during the preceding two months the numbers were between sixty and seventy. The Stockton sanitary authority has decided to purchase the property belonging to the late Dr. Oliver in order to erect a temporary hospital. It was stated that there was a farmhouse which could be utilised for the accommodation of the staff, and three acres of land on which concrete foundations could at once be put in, so that a temporary hospital could be erected in two or three days if required.

\section{SCARLATINA IN NEWCASTLE.}

The scarlatina epidemic in the West Jesmond district of Yewcastle is, I have reasons for thinking, not increasing in extent, but cases are nevertheless occurring in other parts of the city; in this, I believe, it follows its usual course--that is, it breaks out, as it were, with fury in a district, wears itself out there, but gradually gets disseminated to other districts before it finally disappears. The Fational Veterinary Association is to meet here todar, and onr active medical officer of health is to read a paper on Comparative Pathology. It is to be hopol that our veterinary and sanitary authorities, acting together, inar attack and clear up some of the moot points in connexion with animal and human disease-for instance, as recards the present scarlatina epidemic in Newcastle.

Sewcastle-on-Tyne, July 17 th.

\section{$\triangle B E R D E E N$.}

(From our oun Correspondent.)

THE $\Lambda$ HER DE N UN I ER ITY. THE summer session was brought to a cluse on Friday, the 13 th inst., and the professional examinations began on Saturlay. A large number of candidates have come forward at this term-viz., cighty-two for the first division of the first examination, and over forty for the second division; forty or more for the second examination, and between thirty and forty for the final.

\section{IRESIGNATION OF PROFESSOR BRAZIER}

Professor Brazier is about to resign, or has already resigned, the Chair of Chemistry, to which he was appointed in 1862. While lecturing to his class last session, he was seized with an illness which has incapacitated him from active duties since; and when it became known that he had resolved to resion, the students held a mass meeting, at which it was unanimously resolved to express their regret that Professor Brazier should find such a step necessary, and their sympathy for him in his illness. The chairman of the meeting said that by the resignation of Professor Brazier they lost not only the oldest and a most respected member of the Senatus, but a thorough student's friend.

THE HEALTH OF THE CITY.

At a meeting of the Public Health Committee, held on the lith inst., the monthly reports of the medical officer of health and the sanitary inspector were submitted. They showed that during the month of June there was a decrease in the number of zymotic diseases from 93 to 41 . At the late of the meeting there were 9 patients in the City Hospital, compared with 59 at the same date last year. During the month there were 180 deaths, equal to a deathrate of 18.40 per 1000 . During the six months ending June 30 th, 550 cases of zymotic diseases were reported, and $£ 5017 s$. were paid to medical practitioners for the reporting of those cases. For the same period last year, the sum paid to medical men was $\mathfrak{£ 3 4 0}$. Aberdeen, July 17 th.

\section{DUBLIN.}

(From our oun Correspondent.)

\section{AMALGAMATION OF THE DUBLIN MEDICAL SCHOOLS.}

I AM not so sanguine as some appear to be of the successful way in which this scheme is progressing. The report of the committee appointed by the Council will come under discussion this evening; but, knowing the details of the proposed scheme as I do, I believe that unless it is modified in some respects there will be considerable uncertainty as regards its ultimate adoption. There are some individual cases of hardship which a scheme which it was declared would be carried out on equitable terms should not countenance; and if the promoters of the amalgamation scheme wish the schools to act harmoniously they must alter in some respects their present arrangements, and render it more equitable and just to all concerned.

\section{SOUTH DUBLIN WORKHOUSE.}

Mr. Rolinson, Local Government Board Inspector, in his half-yearly report as to the condition of this institution, states that the Garclen Infirmary is quite unsuitable for the large number of inmates it is made to accommolate at present. It has no day-room accommodation whatever, the meals are taken in the passagre between the berk, and in the winter the dormitories have to be occupied by day to a considerable extent, an arrangement which is not conducive to health or comfort. The anount of cubic space for each bed in this building is also very small. The nursery sheds and the separation warks are stated to be quite unfit for occupation, and either new sheds on the site of the present ones should he luait, or these two classes should be transferred elsewhere.

\section{SANI'TARY CONUITION OF CORK.}

At a recent meeting of the Corporation a resolution was moved that the domestic scarenging of the city should 